\title{
Nutritional Status of Bariatric Surgery Candidates
}

\author{
Aliaa Al-Mutawa ${ }^{1}$, Alfred Kojo Anderson ${ }^{1}$, Salman Alsabah ${ }^{2, *}$ and Mohammad Al-Mutawa ${ }^{3}$ \\ 1 Department of Food Science and Nutrition, College of Life Sciences, Kuwait University, Kuwait City 13034, \\ Kuwait; round0cube@gmail.com (A.A.-M.); alfanders@gmail.com (A.K.A.) \\ 2 Department of Surgery, College of Medicine, Kuwait University, Kuwait City 13034, Kuwait \\ 3 Computer Science Department, College of Computing Sciences and Engineering, Kuwait University, \\ Kuwait City 13034, Kuwait; Almutawa@cs.ku.edu.kw \\ * Correspondence: salman.alsabah@hsc.edu.kw; Tel.: +965-6666-6911
}

Received: 20 December 2017; Accepted: 8 January 2018; Published: 11 January 2018

\begin{abstract}
Obesity is a global epidemic affecting populations globally. Bariatric surgery is an effective treatment for morbid obesity, and has increased dramatically. Bariatric surgery candidates frequently have pre-existing nutritional deficiencies that might exacerbate post-surgery. To provide better health care management pre- and post-bariatric surgery, it is imperative to establish the nutritional status of prospective patients before surgery. The aim of this study was to assess and provide baseline data on the nutritional status of bariatric candidates. A retrospective study was conducted on obese patients who underwent bariatric surgery from 2008 to 2015. The medical records of 1538 patients were reviewed for this study. Pre-operatively, the most commonly observed vitamin deficiencies were Vitamin D $(76 \%)$ and Vitamin $B_{12}(16 \%)$. Anemia and iron status parameters were low in a considerable number of patients before surgery, as follows: hemoglobin $20 \%$, mean corpuscular volume (MCV) $48 \%$, ferritin $28 \%$, serum iron $51 \%$, and transferrin saturation $60 \%$. Albumin and transferrin were found to be low in 10\% and $9 \%$ of the patients, respectively, prior to surgery. In addition to deficiencies, a great number of patients had hypervitaminosis pre-operatively. Excess levels of Vitamin $\mathrm{B}_{6}(24 \%)$ was the most remarkable. The findings in this study advocate a close monitoring and tailored supplementation pre- and post-bariatric surgery.
\end{abstract}

Keywords: bariatric surgery; obesity; nutrients

\section{Introduction}

Obesity is associated with low micronutrient levels. Although obese individuals have excess energy stores, they are quite often not well nourished. Many obese subjects have already-existing nutritional deficiencies before bariatric procedures. These deficiencies commonly include iron, Vitamin $B_{12}$, thiamin, folate, and Vitamin D [1-3]. Screening and correction of micronutrient deficiencies preoperatively are crucial, as these deficiencies may be more exacerbated following bariatric procedures, leading to devastating conditions.

While several studies have described nutrient status pre- and post-bariatric surgery, there are no publications in the literature that investigate nutritional status pre-surgery among Kuwaiti patients. Moreover, some micronutrient statuses have not been studied extensively. To the best of our knowledge, reports on Vitamin $B_{2}$ status pre-bariatric surgery are scarce. Given the growing practice of bariatric surgery worldwide, and in Kuwait in particular, it would be extremely important to assess the nutritional status prior bariatric surgery to provide an insight into the current nutritional status. The objective of this study was therefore to investigate pre-operative nutritional status among bariatric candidates. This information could assist healthcare teams in getting a better understanding of the present status of the patient, and consequently provide better health care preparation and management pre- and post-bariatric surgery, e.g., through nutritional screening, dietary and supplementation plans, frequency of follow-up in outpatients' clinics, and regularity of blood testing. 


\section{Methods}

\subsection{Subjects}

A retrospective analysis of medical records and bariatric database of 1538 patients who underwent bariatric surgery between October 2008 and September 2015 at Al-Amiri Hospital, Kuwait, was performed. Patients were excluded if they had a history of previous bariatric operations. All ethical protocols were approved by the Ministry of Health, Kuwait.

Pre-operatively, patients were assessed using a multidisciplinary approach to evaluate surgical eligibility. Pre-operative assessments included medical background, anthropometric measurements, nutritional evaluation, abdominal ultrasound, and upper gastrointestinal endoscopy. Nutritional parameters that were evaluated among the bariatric surgery candidates followed in this study were albumin, transferrin, Vitamin $B_{1}$, Vitamin $B_{2}$, Vitamin $B_{6}$, folate, Vitamin $B_{12}$, Vitamin $D$, Red Blood Cell (RBC), hemoglobin, hematocrit, Mean Corpuscular Volume (MCV), ferritin, iron, and transferrin saturation.

Blood samples were obtained and analyzed according to standard laboratory protocols employed by the hospital for routine analysis, and the reference ranges adopted for this study are shown in Table 1. Nutritional deficiency or excess levels were defined as a concentration below or above the normal reference range of the hospital laboratory.

Ethical approval to conduct the study was obtained from the Ministry of Health and Kuwait Institute for Medical Specialization Ethical Approval Board (Date of approval: 9 February 2016; ethical approcal code 207). Written informed consent was obtained from all participants.

\subsection{Statistical Analysis}

Data were coded and analyzed using SPSS Version 24 (IBM Corp, Armonk, NY, USA), GraphPad Prism Version 7 (GraphPad Software, La Jolla, CA, USA), and Microsoft Excel 2010 (Microsoft Office Professional Plus 2010). Data were tested for normality using Shapiro-Wilk test and Skewness-Kurtosis test. Descriptive statistics—namely, mean \pm Standard Deviation (SD) or \%-were used as appropriate. Differences between mean values in two groups (Male vs. Female) were analyzed using independent samples $t$-test or Mann-Whitney $U$ test. For all statistical tests, $p$ values $\leq 0.05$ were considered statistically significant. 
Table 1. Nutrient status of patients pre bariatric surgery.

\begin{tabular}{|c|c|c|c|c|c|c|}
\hline \multirow{2}{*}{ Nutritional Parameter } & \multirow{2}{*}{ Number of Patients } & \multicolumn{4}{|c|}{ Mean By Gender } & \multirow{2}{*}{ Reference Range } \\
\hline & & Sample Mean \pm SD & Male Mean \pm SD (n) & Female Mean \pm SD $(n)$ & $p$ & \\
\hline Albumin & 1065 & $38.4 \pm 3.0$ & $39.5 \pm 3.0(288)$ & $38.0 \pm 3.0(777)$ & $0.000 *$ & $35-48 \mathrm{~g} / \mathrm{L}$ \\
\hline Transferrin & 97 & $2.8 \pm 0.5$ & $2.7 \pm 0.6(27)$ & $2.9 \pm 0.5(70)$ & 0.120 & $2.15-3.8 \mathrm{~g} / \mathrm{L}$ \\
\hline Vitamin $\mathbf{B}_{1}$ & 637 & $65.0 \pm 28.0$ & $72.3 \pm 35.6(187)$ & $62.0 \pm 23.5(450)$ & $0.000 *$ & $20-100 \mathrm{ng} / \mathrm{mL}$ \\
\hline Vitamin $B_{2}$ & 420 & $245.5 \pm 80.6$ & $258.0 \pm 103.4(120)$ & $341.5 \pm 68.7(300)$ & 0.058 & $75-300 \mathrm{ng} / \mathrm{mL}$ \\
\hline Vitamin $B_{6}$ & 630 & $28.4 \pm 27.2$ & $33.9 \pm 40.9(183)$ & $26.1 \pm 18.7(447)$ & 0.001 * & $7-30 \mathrm{ng} / \mathrm{mL}$ \\
\hline Folate & 306 & $23.0 \pm 9.0$ & $21.8 \pm 8.9(84)$ & $23.4 \pm 9.1(222)$ & 0.153 & $7-45 \mathrm{nmol} / \mathrm{L}$ \\
\hline Vitamin $B_{12}$ & 563 & $178.6 \pm 91.4$ & $182.8 \pm 92.0(165)$ & $176.6 \pm 91.2(398)$ & 0.464 & $\begin{array}{c}<107 \mathrm{pmol} / \mathrm{L} \text { Deficient; 107-133 pmol/L Indeterminate } \\
\text { 133-675 pmol/L Normal }\end{array}$ \\
\hline $25(\mathrm{OH})$ Vitamin D & 610 & $37.0 \pm 31.0$ & $30.0 \pm 21.6(167)$ & $39.6 \pm 33.6(443)$ & $0.001 *$ & $\begin{array}{l}<50 \mathrm{nmol} / \mathrm{L} \text { Deficient; } 50-75 \mathrm{nmol} / \mathrm{L} \text { Insufficient; } \\
>75 \mathrm{nmol} / \mathrm{L} \text { Sufficient; }>250 \mathrm{nmol} / \mathrm{L} \text { Critical High }\end{array}$ \\
\hline RBC & 1079 & $4.9 \pm 0.5$ & $5.2 \pm 0.6(292)$ & $4.8 \pm 0.5(787)$ & $0.000 *$ & Male: $4.5-5.5\left(10^{12} / \mathrm{L}\right) ;$ Female: $3.8-4.8\left(10^{12} / \mathrm{L}\right)$ \\
\hline Hemoglobin & 1079 & $133.4 \pm 15.3$ & $145.4 \pm 15.2(292)$ & $129.0 \pm 12.7(787)$ & 0.000 * & Male: $130-170$ g/L; Female: $120-150$ g/L \\
\hline Hematocrit & 1079 & $0.40 \pm 0.04$ & $0.43 \pm 0.04(292)$ & $0.39 \pm 0.03(787)$ & $0.000 *$ & Male: $0.4-0.5 \mathrm{~L} / \mathrm{L}$; Female: $0.36-0.46 \mathrm{~L} / \mathrm{L}$ \\
\hline MCV & 1079 & $82.1 \pm 6.8$ & $83.6 \pm 6.4(292)$ & $81.5 \pm 6.9(787)$ & $0.000 *$ & $\begin{array}{l}<83 \text { fL Microcytic; 83-101 fL Normocytic; } \\
>101 \text { fL Macrocytic }\end{array}$ \\
\hline Ferritin & 78 & $46.0 \pm 65.1$ & $123.2 \pm 108.5(14)$ & $29.4 \pm 34.8(64)$ & $0.000 *$ & Male: $23.9-336.2 \mathrm{ng} / \mathrm{mL}$; Female: $11-306.8 \mathrm{ng} / \mathrm{mL}$ \\
\hline Iron & 102 & $11.9 \pm 6.5$ & $12.0 \pm 4.7(22)$ & $11.9 \pm 6.9(80)$ & 0.939 & $11-28 \mu \mathrm{mol} / \mathrm{L}$ \\
\hline Transferrin Saturation & 97 & $18.2 \pm 11.3$ & $23.3 \pm 15.8(27)$ & $16.3 \pm 8.6(70)$ & $0.006^{*}$ & $20-40 \%$ \\
\hline
\end{tabular}




\section{Results}

\subsection{Demographic}

The demographic baseline characteristics of the patients studied are shown in Table 2. The study included $1123(73 \%)$ female and $415(27 \%)$ male patients. The great majority of patients were Kuwaitis $(89 \%)$. The mean age of patients was $35 \pm 11.2$ years. All patients underwent a laparoscopic sleeve gastrectomy (LSG). Pre-operative mean weight was $123.8 \pm 24.3 \mathrm{~kg}$, and body mass index (BMI) was $46.1 \pm 8.0 \mathrm{~kg} / \mathrm{m}^{2}$. This corresponds to an average excess weight of $56.5 \pm 21.7 \mathrm{~kg}$ before operation.

Table 2. Study demographics.

\begin{tabular}{cc}
\hline Demographics & Mean \pm SD \\
\hline Age (years) & $35 \pm 11.2$ \\
Height (cm) & $163.8 \pm 9.0$ \\
Weight (kg) & $123.8 \pm 24.3$ \\
Body mass index (BMI) $\left(\mathbf{k g} / \mathbf{m}^{\mathbf{2}}\right)$ & $46.1 \pm 8.0$ \\
EW $(\mathbf{k g})$ & $56.5 \pm 21.7$ \\
\hline
\end{tabular}

\subsection{Protein Status Pre-Bariatric Surgery}

\section{Albumin and Transferrin}

Data for the analyzed nutrients of the bariatric candidates are summarized in Tables 1 and 3 . The average concentration of albumin in the serum specimen of patients was $38.4 \pm 3.0 \mathrm{~g} / \mathrm{L}$. The average for all male patients was $39.5 \pm 3.0 \mathrm{~g} / \mathrm{L}$ and $38.0 \pm 3.0 \mathrm{~g} / \mathrm{L}$ for females. Overall, $10 \%$ of the patients had hypoalbuminemia with concentrations of albumin below the reference range (Table 3).

While the prevalence of high transferrin levels was almost insignificant, the prevalence of low levels was evident, as $9 \%$ of the prospective patients had concentrations of transferrin below the reference range. Overall, mean transferrin levels fell within the normal range of 2.15-3.8 g/L (Table 1). Between the genders, females showed higher $(2.9 \pm 0.5 \mathrm{~g} / \mathrm{L})$ transferrin levels than males $(2.7 \pm 0.6 \mathrm{~g} / \mathrm{L})$, but not significantly.

\subsection{Vitamin Status Pre-Bariatric Surgery}

\subsubsection{Vitamin $B_{1}$}

The prevalence of Vitamin $B_{1}$ deficiency was negligible prior to surgery. The mean level among all patients was $65.0 \pm 28.0 \mathrm{ng} / \mathrm{mL}$ prior to surgery, and was within the normal range $(20-100 \mathrm{ng} / \mathrm{mL})$. Excess cases were more prevalent than deficiencies; pre-operatively, $0.3 \%$ of the patients had Vitamin $B_{1}$ deficiency while $7 \%$ had excess levels of the vitamin. On average, male patients showed significantly higher levels of Vitamin $\mathrm{B}_{1}(72.3 \pm 35.6 \mathrm{ng} / \mathrm{mL})$ than female patients $(62.0 \pm 23.5 \mathrm{ng} / \mathrm{mL})(p=0.000)$; still, all were within normal range (Table 1$)$.

\subsubsection{Vitamin $B_{2}$}

Less than $1 \%$ of patients had Vitamin $B_{2}$ deficiency prior to operation, while $16.7 \%$ had excess levels (Table 3). On the whole, the mean Vitamin $B_{2}$ level $(245.5 \pm 80.6 \mathrm{ng} / \mathrm{mL})$ was within the normal range before surgery. However, male patients were more frequently observed with higher Vitamin $B_{2}$ level $(258 \pm 103.4 \mathrm{ng} / \mathrm{mL})$ than females $(241.5 \pm 68.7 \mathrm{ng} / \mathrm{mL})$ before surgery.

\subsubsection{Vitamin $\mathrm{B}_{6}$}

Among the population studied, no cases of Vitamin $\mathrm{B}_{6}$ deficiency were identified, while there were excess levels in a remarkable $24.1 \%$ of patients, pre-operatively. However, on average, the mean level of $28.4 \pm 27.2 \mathrm{ng} / \mathrm{mL}$ among all patients was within the normal range. On a gender basis, 
the mean values were $33.9 \pm 40.9 \mathrm{ng} / \mathrm{mL}$ and $26.1 \pm 18.7 \mathrm{ng} / \mathrm{mL}$ for males and females, respectively, and were significantly different $(p=0.001)$.

\subsubsection{Folate}

None of the patients was identified with folate deficiency before surgery, while $3.3 \%$ had excess levels. The observed mean serum folate level of $23.0 \pm 9.0 \mathrm{mmol} / \mathrm{L}$ was within the normal range, and female patients showed higher levels $(23.4 \pm 9.1 \mathrm{mmol} / \mathrm{L})$ than males $(21.8 \pm 8.9 \mathrm{mmol} / \mathrm{L})$, although not significantly.

Table 3. Prevalence of deficient and excess nutrient levels pre bariatric surgery.

\begin{tabular}{|c|c|c|c|}
\hline Nutritional Parameter & Number of Patients & $\%$ Deficient/Low & $\%$ Excess \\
\hline Albumin & 1065 & 10.1 & 0 \\
\hline Transferrin & 97 & 9.0 & 3.0 \\
\hline Vitamin $B_{1}$ & 637 & 0.3 & 7.0 \\
\hline Vitamin $\mathbf{B}_{2}$ & 420 & 0.7 & 16.7 \\
\hline Vitamin $\mathbf{B}_{6}$ & 630 & 0 & 24.1 \\
\hline Folate & 306 & 0 & 3.3 \\
\hline Vitamin $B_{12}$ & 563 & 16.4 & 0.4 \\
\hline $25(\mathrm{OH})$ Vitamin D & 610 & 75.6 & 0.2 \\
\hline RBC & 1079 & 3.1 & 0 \\
\hline \multicolumn{4}{|l|}{ Hemoglobin } \\
\hline Both Genders & 1079 & 19.6 & 0 \\
\hline Male & 292 & 14.4 & \\
\hline Female & 787 & 21.6 & \\
\hline \multicolumn{4}{|l|}{ Hematocrit } \\
\hline Both Genders & 1079 & 18.4 & 0 \\
\hline Male & 292 & 17.8 & \\
\hline Female & 787 & 18.6 & \\
\hline MCV & 1079 & 47.9 & 0 \\
\hline \multicolumn{4}{|l|}{ Ferritin } \\
\hline Both Genders & 78 & 28.2 & 0 \\
\hline Male & 14 & 21.4 & \\
\hline Female & 64 & 29.7 & \\
\hline Iron & 102 & 50.5 & 1.0 \\
\hline Transferrin Saturation & 97 & 59.0 & 2.0 \\
\hline
\end{tabular}

\subsubsection{Vitamin $B_{12}$}

The prevalence of pre-operative Vitamin $\mathrm{B}_{12}$ deficiency was $16.4 \%$, while $0.4 \%$ of the patients had excess levels. The mean serum Vitamin $\mathrm{B}_{12}$ level was $178.6 \pm 91.4 \mathrm{pmol} / \mathrm{L}$, which was within the normal range pre-operatively. Male patients were more frequently observed with higher serum Vitamin $\mathrm{B}_{12}$ levels $(182.8 \pm 93.0 \mathrm{pmol} / \mathrm{L})$ than female patients $(176.6 \pm 91.2 \mathrm{pmol} / \mathrm{L})$, but the differences were not statistically significant $(p>0.05)$.

\subsubsection{Vitamin D}

The majority of patients $(76 \%)$ were Vitamin D deficient before surgery, with a mean level of $37.0 \pm 31.0 \mathrm{nmol} / \mathrm{L}$, and $0.2 \%$ of the sample patients with excess Vitamin D levels. Overall, female patients were indicative of higher Vitamin D levels $(39.6 \pm 33.6 \mathrm{nmol} / \mathrm{L})$ than male patients $(30.0 \pm 21.6 \mathrm{nmol} / \mathrm{L})$, both of which were below the preference range. 


\subsection{Anemia and Iron Status Pre Bariatric Surgery}

\subsubsection{Red Blood Cells (RBC)}

Before surgery, only $3.1 \%$ of the patients were found to have low RBC levels. Mean RBC levels was observed to be $4.9 \pm 0.5 \times 10^{12} / \mathrm{L}$ among all patients. The mean for female patients was $4.8 \pm 0.5 \times 10^{12} / \mathrm{L}$ and for male patients it was $5.2 \pm 0.6 \times 10^{12} / \mathrm{L}$, both of which were within their respective normal ranges.

\subsubsection{Hemoglobin}

Anemia status was assessed based on hemoglobin levels. The mean hemoglobin levels in 1079 patients before surgery were $133.4 \pm 15.3 \mathrm{~g} / \mathrm{L}$, which was within the normal range. However, the data indicated that $19.6 \%$ of the patients had low hemoglobin levels, and on a gender basis, $14.4 \%$ male and $21.6 \%$ females had low hemoglobin levels prior to surgery. Male patients on average had significantly higher levels $(145.4 \pm 15.2 \mathrm{~g} / \mathrm{L})$ than females $(129.0 \pm 12.7 \mathrm{~g} / \mathrm{L})(p=0.000)$.

\subsubsection{Hematocrit}

Besides using hemoglobin as a parameter, anemia was also assessed by hematocrit levels. Before surgery, the mean level was found to be $0.40 \pm 0.04 \mathrm{~L} / \mathrm{L}$, while on gender basis, the means were $0.43 \pm 0.04 \mathrm{~L} / \mathrm{L}$ and $0.39 \pm 0.03 \mathrm{~L} / \mathrm{L}$ for males and females, respectively. All values were within the normal range. However, $18.4 \%$ of both genders indicated low hematocrit levels, while $17.8 \%$ males and $18.6 \%$ females indicated low hematocrit levels.

\subsubsection{Mean Corpuscular Volume (MCV)}

Before surgery, $47.9 \%$ of the patients had microcytosis while no incidence of macrocytosis was detected. The pre-operative MCV mean value was $82.1 \pm 6.8 \mathrm{fL}$, indicating microcytosis (Table 1). Between genders, male patients had significantly higher MCV mean value $(83.6 \pm 6.4 \mathrm{fL})$ in comparison to female patients $(81.5 \pm 6.9 \mathrm{fL})(p=0.000)$. Thus, while male patients were within the normocytic level, female patients showed microcytic levels pre-operatively.

\subsubsection{Ferritin}

Low ferritin levels were noted in $28.2 \%$ of the patients before surgery, while there was no record of excess ferritin in any of the patients (Table 3). The mean value for all patients was $46.0 \pm 65.1 \mathrm{ng} / \mathrm{mL}$, and males had a significantly higher mean than females $(p=0.000)$ at $123.2 \pm 108.5 \mathrm{ng} / \mathrm{mL}$ and $29.4 \pm 34.8 \mathrm{ng} / \mathrm{mL}$, respectively. Overall, mean ferritin levels were well within the normal range before surgery (Table 1).

\subsubsection{Iron}

The mean serum iron level in all patients was $11.9 \pm 6.5 \mu \mathrm{mol} / \mathrm{L}$, which was within the normal range. However, low serum iron levels were observed in almost half of the patients $(50.5 \%)$ pre-operatively (Table 3), with only 1\% showing excess. Overall, mean serum iron levels were almost within the normal range before surgery, and both males and females had almost the same level of serum iron, $12.0 \pm 4.7 \mu \mathrm{mol} / \mathrm{L}$ and $11.9 \pm 6.9 \mu \mathrm{mol} / \mathrm{L}$, respectively.

\subsubsection{Transferrin Saturation}

The mean transferrin saturation determined was $18.2 \pm 11.3 \%$. A great number of patients $(59 \%)$ were found with low transferrin saturation levels (<20\%) (Table 3), which implies a high prevalence of iron deficiency. On a gender basis, males had a higher value of $23.3 \pm 15.8 \%$, which was within the normal range, while females were significantly deficient $(16.3 \pm 8.6 \%)$. 


\section{Discussion}

\subsection{Nutritional Deficiencies Pre Bariatric Surgery}

Several studies have examined nutritional deficiencies among morbidly obese patients prior to bariatric procedures. Schweiger et al. [4] studied nutritional deficiencies in 114 bariatric candidates who underwent surgery between 2006 and 2008. The prevalence of pre-operative nutritional deficiencies was $35 \%$ for iron, $24 \%$ for folate, $24 \%$ for ferritin, $3.6 \%$ for Vitamin $\mathrm{B}_{12}, 2 \%$ for phosphorous, and $0.9 \%$ for calcium. Hemoglobin and Mean Corpuscular Volume (MCV) levels were low in 19\% of the patients. High levels of Parathyroid Hormone (PTH) were found among 39\% of the patients. No hypoalbuminemia was encountered. Low iron and ferritin were more common in females than males ( 40.8 vs. $14.3 \%$ ) and (31.8 vs. $0 \%$ ), respectively. Similarly, another study conducted by Al-Mulhim [5] prospectively evaluated nutritional status in 112 patients. Pre-operatively, 64\% of the patients had one deficiency, and $11 \%$ had more than one. Deficiencies rates were reported as follows: hemoglobin $24 \%$, iron $11.6 \%$, Vitamin D 60\%, Vitamin $\mathrm{B}_{12} 1.8 \%$, and folate $0.9 \%$.

According the latest report from the 2017 International Federation of Surgical Obesity global registry Kuwait (100.0\%), Australia (100.0\%) and Saudi Arabia (100.0\%) submitted and reported the highest rates of sleeve gastrectomy operations [6]. This data illustrates the importance of investigating the nutritional effects of LSG on bariatric patients in Kuwait. Data from this study showed that bariatric surgery candidates had pre-existing nutritional deficiencies, which included Vitamin D, iron, Vitamin $B_{12}$, and protein. Similar conditions of micronutrient deficiencies have been found in morbidly obese patients prior sleeve gastrectomy [7]. The importance of pre-assessment of the nutritional status of bariatric surgery candidates has also been reported previously $[4,8]$. Nutritional deficiencies among bariatric surgery candidates are commonly attributed to unhealthy dietary and lifestyle habits $[9,10]$, including consumption of non-varied, high-calorie and high-fat diets. Obese individuals often displace nutritious foods with high-calorie foods that are rich in refined carbohydrates and fat. Moreover, chronic dieting, which is common among obese individuals, might further deteriorate their nutritional status as a result of food restrictions. Aside from diet and lifestyle, a further explanation involves the volumetric dilution factor. Obese individuals have relatively high amounts of total body water, and their extracellular compartment appears to be more expanded than the intracellular compartment [11]. Aasheim et al. [10] suggested that low micronutrient levels might be related to the dilution effect of the extracellular fluid on micronutrient concentrations.

\subsection{Protein Deficiency Pre Bariatric Surgery: Albumin and Transferrin}

Albumin and transferrin levels were used as potential indicators for protein status, and were low in about $10 \%$ of the studied patients pre-operatively. This might indicate that the great majority ( 90\%) of the bariatric candidates had sufficient protein intake. This finding is in line with the reported protein intake in the general population of Kuwait. According to the national nutrition survey in Kuwait, the estimated protein intake was $110 \mathrm{~g} /$ day in males and $67 \mathrm{~g} /$ day in females [12]. These correspond to a $99.6 \%$ and $98.4 \%$ of males and females, respectively, who met the Acceptable Macronutrient Distribution Range (AMDR).

Reports of albumin status vary widely in the literature, with the percentage of low albumin ranging from 0 to $27 \%$ before bariatric surgery [4,7,13-15]. It is important to note that albumin and transferrin levels do not always reflect actual protein status, since they are affected by other conditions, including inflammation, liver disease, and nephrotic syndrome, which were not investigated in this study [16]. Since obesity is associated with chronic low-grade inflammation, acute phase protein levels, including albumin and transferrin, might be altered [17]. Hence, the observed low levels of albumin and transferrin in the current study should be carefully interpreted, as they may not necessarily indicate insufficient protein intake. 


\subsection{Vitamin Deficiencies Pre Bariatric Surgery}

\subsubsection{B Vitamin Deficiencies Pre Bariatric Surgery}

Vitamin $B_{12}$ was the only $B$ vitamin that showed considerable deficiency prevalence (16.4\%) prior to surgery (Table 3). Vitamin $B_{12}$ deficiency findings were in line with earlier studies $(13-16 \%)[7,18,19]$, nevertheless, $\mathrm{B}_{12}$ deficiency proved to be lower in the general population of Kuwait, with $1.3 \%$ of males and $5.6 \%$ of females showing deficiencies [20]. However, several studies have also reported significant deficiencies in Vitamin $\mathrm{B}_{1}, \mathrm{~B}_{6}$, and folate, which contradict the current findings $[4,7,13,14,18]$. These variations in B Vitamin statuses may be partially explained by the differences in the extent of food fortifications between countries. It could also be related to food and supplement intake, which was not assessed in this study. According to the national nutrition survey in Kuwait, the mean intake of Vitamins $B_{1}, B_{2}, B_{6}$ and $B_{12}$ was greater than the Estimated Average Requirement (EAR) values in both genders [12]. Data on folate showed that more than two-thirds of the Kuwaiti population did not meet the EAR [12]. Overall, these findings are comparable to the current findings as negligible deficiency prevalence was observed in Vitamin $B_{1}, B_{2}$, and $B_{6}$. A third possible explanation for the differences between the current data and some literature is the prevailing cultural factor that forbids alcohol consumption. Chronic alcoholism can be a contributing factor to Vitamin $\mathrm{B}_{1}$ and folate deficiencies, as alcohol interferes with the active transport of Vitamin $\mathrm{B}_{1}$ and folate across the intestinal wall and hastens their excretion in urine [16,21,22]. Accordingly, this might justify the negligible prevalence of Vitamin $B_{1}$ and folate deficiencies before surgery in comparison to previous studies.

\subsubsection{Vitamin D Deficiency Pre Bariatric Surgery}

Vitamin D deficiency was the most prevalent before surgery, affecting about $76 \%$ of the surgery candidates (Table 3). This high prevalence of Vitamin D deficiency is consistent with previously reported range of 60-91\% [5,7,13-15]. Regarding the general population in Kuwait, data from Kuwait National Nutritional Survey (KNNS) showed a high prevalence of Vitamin D deficiency among Kuwaiti adults [22]. According to a cross-sectional study of 960 adults enrolled for the KNNS, approximately $56 \%$ of the Kuwaiti adults had Vitamin D inadequacy (25 $(\mathrm{OH}) \mathrm{D}=12-19.9 \mathrm{ng} / \mathrm{mL})$, and $27 \% \mathrm{had}$ Vitamin D deficiency (25 (OH) D $<12 \mathrm{ng} / \mathrm{mL})$ [23]. Molla et al. [24] also assessed Vitamin D levels in Kuwaiti mothers and their neonates in a total of 128 mother-neonate pairs. Data showed that $40 \%$ of the mothers and $60 \%$ of the neonates are Vitamin D deficient on the day of delivery. The high prevalence of Vitamin D deficiency found in the current study is also comparable to other findings from Middle Eastern countries [25]. According to the cross-sectional study involving 834 healthy Saudi Arabian men by Ardawi et al. [26], Vitamin D deficiency was present in $87.8 \%$ of the participants.

Vitamin $\mathrm{D}$ deficiency in the current bariatric candidates can be attributed to several causes. One reason is the decreased dietary consumption of Vitamin D-rich sources, including fortified dairy products. A second reason is the reduced exposure to sunlight due to limited outdoor activities, clothing habits, and use of sunscreen. The psychological status of obese individuals and the cultural and lifestyle factors of the population might further explain the limited sun exposure. A third possible reason for Vitamin D deficiency is the sequestration of Vitamin D in adipose tissues. The degree of adiposity appears to be inversely correlated with Vitamin D levels. Correspondingly, several studies have reported that obese individuals tend to have lower levels of Vitamin D due to its increased uptake in adipose tissue [27-29]. A fourth reason for deficiency might be related to the decreased synthesis of Vitamin D by the liver as a result of impaired liver function due to fatty liver disease, which is common among obese individuals [30]. Lastly, regarding the variation in Vitamin D deficiency prevalence in the literature, it could also be related to the geographical, seasonal, and fortification policy differences.

\subsection{Anemia and Iron Deficiency Pre Bariatric Surgery}

Using low hemoglobin levels as an indicator for anemia, anemia was observed in about $20 \%$ of the bariatric candidates in this study, which supports previously reported values of $18-24 \%[4,5,9,15]$. 
However, anemia has been variably reported in the literature, and others have observed a much lower prevalence $(1-5 \%)[7,13,19]$. The prevalence of anemia according to hemoglobin status was shown to be at a lower level in the general population of Kuwait as compared to bariatric candidates, showing deficiencies in $2.5 \%$ in males and $17.1 \%$ in females aged $20-49$ [20]. Iron, folate, and $B_{12}$ deficiencies are the main contributors to the development of anemia. However, given the low level of iron status parameters in our study population, it can be stated that the observed anemia was mostly due to iron deficiency. Iron biochemical parameters such as ferritin, serum iron, and transferrin saturation indicated poor iron status pre-operatively. Low ferritin was found in $28 \%$ of our patients, which is in good agreement with the $24 \%$ reported by Schweiger et al. [4]. Low serum iron was observed in half of the patients before surgery, which matches the data of Ben-Porat et al. [18] (47\%). On the contrary other previous studies have reported a much lower prevalence in terms of low ferritin (1-10\%) $[7,9,18,31]$ and serum iron levels (7-29\%) [5,15,31,32].

In terms of the prevalence of anemia and iron deficiency in the general Kuwaiti population, data from a cross-sectional study with a sample size of 1830 showed that the prevalence of anemia in adults was 3\% in males and $17 \%$ in females [20]. Similarly, the prevalence of iron deficiency based on low serum ferritin levels was $4 \%$ in males and $19 \%$ in females [20]. In comparison to the general population, the prevalence of anemia and iron deficiency appeared to be higher in our obese sample, and was more noticeable in the male gender.

The high percentages of pre-operative anemia and iron deficiency may be attributed to inadequate iron intake due to poor dietary choices. A second cause of deficiency may include poor adherence to oral iron supplementation by anemic patients due to its gastrointestinal side effects. A third cause of deficiency could be the predominance of the female gender (73\%) in the reproductive age in our sample. Women of reproductive age are at increased risk of iron deficiency anemia due to blood loss through menstruation. Furthermore, blood investigation of ferritin, serum iron, and transferrin saturation were not part of the routine preoperative assessment; hence, these tests may only be requested when deficiencies were suspected.

\subsection{Excess Micronutrient Levels Pre Bariatric Surgery}

In addition to deficiency findings, some patients were found to have excess micronutrient levels, which is consistent with data reported by van Rutte et al. [7]. These excess levels might be due to the consumption of large doses of over-the-counter supplements by the patient's own initiative, or by intense preoperative nutritional optimization from healthcare providers.

Excess levels were seen for all the investigated vitamins; however, Vitamin $\mathrm{B}_{6}$ was the most remarkable. Vitamin $B_{6}$ was found in excess levels among $24.1 \%$ of the bariatric surgery candidates. This data is similar to a previous report of Vitamin $B_{6}$ hypervitaminosis being found in $21 \%$ of pre-operative patients [7]. Regarding the mean levels, male patients in the current study showed excess Vitamin $B_{6}$ with average plasma concentrations of $33.9 \mathrm{ng} / \mathrm{mL}$, compared to the normal range of 7-30 ng/mL. Excessive increase in Vitamin $B_{6}$ levels might lead to sensory neuropathy with gait changes, peripheral sensation, and lack of muscle coordination [22]. Like other B vitamins, Vitamin $B_{6}$ is water soluble, and thus is easily eliminated in urine. Therefore, toxicity due to $\mathrm{B}_{6}$ is unlikely at reasonable daily doses, but it has been reported that regular consumption of as little as $200 \mathrm{mg}$ could cause adverse effects [33]. As for folate toxicity, it is considered low. However, high intake of folate from supplements may obscure signs of Vitamin $B_{12}$ deficiency [22]. If Vitamin $B_{12}$ deficiency is left untreated, serious neurological damage may occur. Regarding Vitamin $\mathrm{B}_{1}$, some reports have described toxicity symptoms including anxiety, pruritus, respiratory distress, nausea, abdominal pain, and shock [22]. It is important to note that neither supplement intake nor clinical manifestations of vitamins toxicity have been investigated in the present study. Consequently, it is hard to know whether the observed excess levels are of any clinical relevance. 


\section{Conclusions}

The rising prevalence of obesity is causing a parallel increase in the use of bariatric surgery. Nutritional status is one of the main concerns in the bariatric field. Since nutritional deficiencies are common among obese individuals, nutritional assessment and optimization before bariatric surgery is crucial to avoiding further deterioration post surgery. In this study, nutritional deficiencies were found to exist in patients prior to bariatric surgery. Vitamin $D$, Vitamin $B_{12}$, and iron deficiencies were the most commonly observed before surgery, which suggests more consideration should be given to these micronutrients. Female patients of childbearing age deserve particular attention in term of anemia and iron status. On the other hand, data regarding Vitamin $B_{2}$ do not suggest a need for intense supplementation and monitoring. The current data highlights the importance of pre-operative nutritional screening and optimization. It is important to note that nutritional supplementation should be tailored to patient laboratory tests to prevent excessive increases in micronutrient levels.

Acknowledgments: The authors are grateful to the Department of Food Science and Nutrition at Kuwait University for its support for this work, and the Al-Amiri Hospital for facilitating data accessibility.

Author Contributions: The study was conceived and designed by Aliaa Al-Mutawa, Alfred Kojo Anderson and Salman Alsabah. Data acquisition and extraction were done by Aliaa Al-Mutawa and Mohammad Al-Mutawa. Drafting and critical revision of the manuscript was by Alfred Kojo Anderson. Study supervision was by Salman Alsabah. All authors approved the final version of the manuscript.

Conflicts of Interest: The authors declare no conflict of interest.

\section{References}

1. Bordalo, L.; Sales Teixeira, T.; Bressan, J.; Mourão, D. Bariatric surgery: How and why to supplement. Rev. Assoc. Méd. Bras. 2011, 57, 111-118. [CrossRef]

2. Shankar, P.; Boylan, M.; Sriram, K. Micronutrient deficiencies after bariatric surgery. Nutrition 2010, 26, 1031-1037. [CrossRef] [PubMed]

3. Ziegler, O.; Sirveaux, M.; Brunaud, L.; Reibel, N.; Quilliot, D. Medical follow up after bariatric surgery: Nutritional and drug issues General recommendations for the prevention and treatment of nutritional deficiencies. Diabetes Metab. 2009, 35, 544-557. [CrossRef]

4. Schweiger, C.; Weiss, R.; Berry, E.; Keidar, A. Nutritional Deficiencies in Bariatric Surgery Candidates. Obes. Surg. 2010, 20, 193-197. [CrossRef] [PubMed]

5. Al-Mulhim, A. Laparoscopic Sleeve Gastrectomy and Nutrient Deficiencies. Surg. Laparosc. Endosc. Percutaneous Tech. 2016, 26, 208-211. [CrossRef] [PubMed]

6. Higa, K. Third IFSO Global Registry Report 2017; Dendrite Clinical Systems Limited: Henley-on-Thames, UK, 2017.

7. Van Rutte, P.; Aarts, E.; Smulders, J.; Nienhuijs, S. Nutrient Deficiencies Before and After Sleeve Gastrectomy. Obes. Surg. 2014, 24, 1639-1646. [CrossRef] [PubMed]

8. Ernst, B.; Thumheer, M.; Schmid, S.M. Evidence for the necessity to systematically assess micronutrient status prior to bariatric surgery. Obes. Surg. 2009, 19, 66-73. [CrossRef] [PubMed]

9. Moizé, V.; Deulofeu, R.; Torres, F.; de Osaba, J.; Vidal, J. Nutritional Intake and Prevalence of Nutritional Deficiencies Prior to Surgery in a Spanish Morbidly Obese Population. Obes. Surg. 2011, 21, 1382-1388. [CrossRef] [PubMed]

10. Aasheim, E.; Hofsø, D.; Hjelmesæth, J.; Birkeland, K.I.; Bøhmer, T. Vitamin status in morbidly obese patients: A cross-sectional study. Am. J. Clin. Nutr. 2008, 87, 362-369. [PubMed]

11. Waki, M.; Kral, J.G.; Mazariegos, M.; Wang, J.; Pierson, R.N.; Heymsfield, S.B. Relative expansion of extracellular fluid in obese vs. nonobese women. Am. J. Physiol. 1991, 261, E199-E203. [CrossRef] [PubMed]

12. Zaghloul, S.; Al-Hooti, S.; Al-Hamad, N.; Al-Zenki, S.; Alomirah, H.; Alayan, I.; Al-Attar, H.; Al-Othman, A.; Al-Shami, E.; Al-Somaie, M.; et al. Evidence for nutrition transition in Kuwait: Over-consumption of macronutrients and obesity. Public Health Nutr. 2012, 16, 596-607. [CrossRef] [PubMed]

13. Coupaye, M.; Rivière, P.; Breuil, M.; Castel, B.; Bogard, C.; Dupré, T.; Flamant, M.; Msika, S.; Ledoux, S. Comparison of Nutritional Status During the first year after sleeve gastrectomy and Roux-en-Y Gastric Bypass. Obes. Surg. 2014, 24, 276-283. [CrossRef] [PubMed] 
14. Moizé, V.; Andreu, A.; Flores, L.; Torres, F.; Ibarzabal, A.; Delgado, S.; Lacy, A.; Rodriguez, L.; Vidal, J. Long-Term Dietary Intake and Nutritional Deficiencies following Sleeve Gastrectomy or Roux-En-Y Gastric Bypass in a Mediterranean Population. J. Acad. Nutr. Diet. 2013, 113, 400-410. [CrossRef] [PubMed]

15. Saif, T.; Strain, G.; Dakin, G.; Gagner, M.; Costa, R.; Pomp, A. Evaluation of nutrient status after laparoscopic sleeve gastrectomy 1, 3, and 5 years after surgery. Surg. Obes. Relat. Dis. 2012, 8, 542-547. [CrossRef] [PubMed]

16. Mahan, L.; Escott-Stump, S. Krause's Food Nutrition Therapy, 12th ed.; Saunders/Elsevier: St. Louis, MO, USA, 2008; pp. 84-85, 414, 1229.

17. Wellen, K.E.; Hotamisligil, G.S. Inflammation, stress, and diabetes. J. Clin. Investig. 2005, 115, 1111-1119. [CrossRef] [PubMed]

18. Ben-Porat, T.; Elazary, R.; Yuval, J.; Wieder, A.; Khalaileh, A.; Weiss, R. Nutritional deficiencies after sleeve gastrectomy: Can they be predicted preoperatively? Surg. Obes. Relat. Dis. 2015, 11, 1029-1036. [CrossRef] [PubMed]

19. Gjessing, H.; Nielsen, H.; Mellgren, G.; Gudbrandsen, O. Energy intake, nutritional status and weight reduction in patients one year after laparoscopic sleeve gastrectomy. Springerplus 2013, 2, 352. [CrossRef] [PubMed]

20. Al-Zenki, S.; Alomirah, H.; Al Hooti, S.; Al Hamad, N.; Jackson, R.T.; Rao, A.; Al Jahmah, N.; Al Obaid, I.; Al Ghanim, J.; Al Somaie, M.; et al. Prevalence and Determinants of Anemia and Iron Deficiency in Kuwait. Int. J. Environ. Res. Public Health 2015, 12, 9036-9045. [CrossRef] [PubMed]

21. Gastaldi, G.; Casirola, D.; Ferrari, G.; Rindi, G. Effect of chronic ethanol administration on thiamine transport in microvillous vesicles of rat small intestine. Alcohol Alcohol. 1989, 24, 83-89. [CrossRef] [PubMed]

22. Food and Nutrition Board. Dietary Reference Intakes for Thiamin, Riboflavin, Niacin, Vitamin B b6 s, Folate, Vitamin B b12 s, Pantothenic Acid, Biotin, and Choline; National Academy Press: Washington, DC, USA, 1998; pp. 81, 182, 203-204, 211, 273.

23. Zhang, F.; Al Hooti, S.; Al Zenki, S.; Alomirah, H.; Jamil, K.; Rao, A.; Al Jahmah, N.; Saltzman, E.; Ausman, L.M. Vitamin D deficiency is associated with high prevalence of diabetes in Kuwaiti adults: Results from a national survey. BMC Public Health 2016, 16, 100. [CrossRef] [PubMed]

24. Molla, A.; Al Badawi, M.; Hammoud, M.; Molla, A.; Shukkur, M.; Thalib, L.; Eliwa, M. Vitamin D status of mothers and their neonates in Kuwait. Pediatr. Int. 2005, 47, 649-652. [CrossRef] [PubMed]

25. El-Hajj Fuleihan, G. Vitamin D Deficiency in the Middle East and its Health Consequences for Children and Adults. Clin. Rev. Bone Miner. Metab. 2009, 7, 77-93. [CrossRef]

26. Ardawi, M.; Sibiany, A.; Bakhsh, T.; Qari, M.; Maimani, A. High prevalence of vitamin D deficiency among healthy Saudi Arabian men: Relationship to bone mineral density, parathyroid hormone, bone turnover markers, and lifestyle factors. Osteoporos. Int. 2012, 23, 675-686. [CrossRef] [PubMed]

27. Vanlint, S. Vitamin D and Obesity. Nutrients 2013, 5, 949-956. [CrossRef] [PubMed]

28. Tsiaras, W.; Weinstock, M. Factors Influencing Vitamin D Status. Acta Derm. Venereol. 2011, 91, 115-124. [CrossRef] [PubMed]

29. Holick, M.F. Vitamin D deficiency. N. Engl. J. Med. 2007, 357, 266-281. [CrossRef] [PubMed]

30. Bell, N.; Epstein, S.; Greene, A.; Shary, J.; Oexmann, M.; Shaw, S. Evidence for alteration of the vitamin D-endocrine system in obese subjects. J. Clin. Investig. 1985, 76, 370-373. [CrossRef] [PubMed]

31. Toh, S.; Zarshenas, N.; Jorgensen, J. Prevalence of nutrient deficiencies in bariatric patients. Nutrition 2009, 25, 1150-1156. [CrossRef] [PubMed]

32. Damms-Machado, A.; Friedrich, A.; Kramer, K.; Stingel, K.; Meile, T.; Küper, M.; Königsrainer, A.; Bischoff, S.C. Pre- and Postoperative Nutritional Deficiencies in Obese Patients Undergoing Laparoscopic Sleeve Gastrectomy. Obes. Surg. 2012, 22, 881-889. [CrossRef] [PubMed]

33. Christensen, S. Vitamin B6 Overdose Amount. Available online: https://www.livestrong.com/article/ 438301-what-is-vitamin-b6-used-for/ (accessed on 23 November 2017).

(C) 2018 by the authors. Licensee MDPI, Basel, Switzerland. This article is an open access article distributed under the terms and conditions of the Creative Commons Attribution (CC BY) license (http://creativecommons.org/licenses/by/4.0/). 